\title{
AVALIAÇÃO EM LARGA ESCALA E BASE NACIONAL COMUM CURRICULAR (BNCC): DIMENSÕES DA POLÍTICA DE CONTENÇÃO E LIBERAÇÃO NO BRASIL $^{1}$
}

\author{
EVALUACIÓN A GRAN ESCALA Y BASE NACIONAL COMÚN CURRICULAR \\ (BNCC): DIMENSIONES DE LA POLÍTICA DE CONTENCIÓN Y LIBERACIÓN EN \\ BRASIL
}

\begin{abstract}
LARGE-SCALE EVALUATION AND COMMON NATIONAL CURRICULUM BASE (BNCC): DIMENSIONS OF THE POLICY OF CONTAINMENT AND RELEASE IN $B R A Z I L$
\end{abstract}

\author{
Amanda Melchiotti GONÇALVES ${ }^{2}$ \\ Dhyovana GUERRA ${ }^{3}$ \\ Roberto Antonio DEITOS ${ }^{4}$
}

RESUMO: Este artigo tem o objetivo de desenvolver uma reflexão acerca da avaliação em larga escala, a partir da $\operatorname{BNCC}(2017 ; 2018)$, como uma dimensão da política de contenção e de liberação no Brasil. Para tanto, discorre-se acerca da relação entre a avaliação em larga escala e a BNCC, levando-se em conta o discurso dos Organismos Internacionais, que por sua vez, maximizam a busca estrita por resultados. Desse modo, apresenta-se a BNCC e seus principais apoiadores, a fim de explicitar a reforma empresarial na educação e a intencionalidade da avaliação em larga escala apresentada no documento. Logo, a constatação é de que a BNCC expressa a contenção/restrição do acesso aos conteúdos científicos, bem como o controle e a padronização almejada nas avaliações em larga escala por meio da política de liberação dos chamados conteúdos socioemocionais como norteadores da aprendizagem.

PALAVRAS-CHAVE: Base Nacional Comum Curricular. Política de contenção e liberação. Avaliação em larga escala.

\footnotetext{
${ }^{1}$ Este artigo é composto de parte das reflexões desenvolvidas nas Dissertações de Mestrado apresentadas ao Programa de Pós-Graduação em Educação da Universidade Estadual do Oeste do Paraná - Campus de Cascavel, "Contenção e liberação na política educacional brasileira: tendências predominantes na política de Educação Infantil e do Ensino Fundamental (2006 - 2016)", orientada pela Dra. Ireni Marilene Zago Figueiredo e "Os intelectuais orgânicos da Base Nacional Comum Curricular (BNCC): aspectos teóricos e ideológicos", orientada pelo Dr. Roberto Antonio Deitos.

${ }^{2}$ Universidade Estadual do Oeste do Paraná (UNIOESTE), Cascavel - PR - Brasil. Doutoranda no Programa de Pós-graduação em Educação. ORCID: https://orcid.org/0000-0002-8600-6248. E-mail: amandamelchiottigoncalves@gmail.com

${ }^{3}$ Universidade Estadual do Oeste do Paraná (UNIOESTE), Cascavel - PR - Brasil. Doutoranda no Programa de Pós-graduação em Educação. ORCID: https://orcid.org/0000-0002-1026-606X. E-mail: dhyovanaguerra@hotmail.com

${ }^{4}$ Universidade Estadual do Oeste do Paraná (UNIOESTE), Cascavel - PR - Brasil. Professor no curso de Pedagogia e no Programa de Pós-Graduação em Educação. Doutor em Educação (UNICAMP). ORCID: https://orcid.org/0000-0001-9150-6354.E-mail: rdeitos@uol.com.br
} 
RESUMEN: Este articulo tiene como objetivo desarrollar una reflexión sobre la evaluación a gran escala, a partir de la BNCC (2017; 2018), como dimensión de la política de contención y liberación en Brasil. Con este fin, se discute la relación entre la evaluación a gran escala y la BNCC, teniendo en cuenta el discurso de las organizaciones internacionales, que a su vez maximizan la búsqueda estricta de resultados. De esta manera, la BNCC y sus principales partidarios se presentan para explicar la reforma empresarial en educación y la intencionalidad de la evaluación a gran escala presentada en el documento. Por lo tanto, la observación es que la BNCC expresa la contención / restricción del acceso al contenido científico, así como el control y la estandarización dirigidos a evaluaciones a gran escala a través de la política de liberación de los llamados contenidos socioemocionales como guías para el aprendizaje.

PALABRAS CLAVE: Base Curricular Nacional Común. Politica de contención y liberación. Evaluación a gran escala.

ABSTRACT: This article aims to develop a reflection on large-scale assessment, from the BNCC (2017; 2018), as a dimension of the containment policy in Brazil. To this end, the relationship between large-scale assessment and BNCC is discussed, taking into account the discourse of International Organizations, which in turn maximize the strict search for results. In this way, BNCC and its main supporters are introduced in order to explain the business reform in education and the intentionality of the large-scale assessment presented in the document. Therefore, the observation is that the BNCC expresses the containment / restriction of access to scientific content, as well as the control and standardization aimed at large-scale evaluations through the policy of releasing so-called socio-emotional content as guides for learning.

KEYWORDS: Common National Curricular Base. Containment and release policy. Largescale evaluation.

\section{Introdução}

A avaliação educacional, no sentido estrito de ranqueamento dos resultados, é um dos componentes do discurso dos Organismos Internacionais que expressa o controle e a busca pela maximização dos resultados da educação no desenvolvimento econômico, social e no alívio dos efeitos da pobreza como receituários para as políticas sociais. Não obstante, a avaliação em larga escala se torna o eixo de monitoramento e controle estruturante da política educacional brasileira a partir de 1990, e passou a influenciar e direcionar os mecanismos para as políticas de gestão e financiamento da educação e as políticas curriculares nacionais.

A Base Nacional Comum Curricular (BNCC), neste contexto, representa a atual reforma curricular brasileira. Consequentemente, projeta mudanças em todos os âmbitos organizativos do sistema educacional do país; assim, a avaliação, a partir da BNCC, corrobora 
com o objetivo de atingir a padronização e a busca pelos resultados na educação, oferecendo mecanismos gerenciais e de controle das políticas.

Para a discussão sobre a avaliação em larga escala no Brasil, a partir dos preceitos da BNCC, recorre-se aos conceitos de política de contenção e liberação, discutidos por Cunha (1979). As políticas de contenção e liberação, na política educacional brasileira da década de 1970, expressam, respectivamente, determinadas barreiras de contenção que impedem/barram a elevação dos níveis de escolaridade e, no segundo caso, proporcionam a ampliação ou a elevação dos níveis de escolaridade (CUNHA, 1979). Nessa perspectiva, contenção e a liberação são processos que respondem à política educacional da década de 1970 e, do mesmo modo, a partir de 1990, e se expressam, em parte, no ordenamento normativo brasileiro, em que são tendências predominantes na política de educação básica (GUERRA, 2020).

Os processos de contenção podem ser observados, por exemplo, nos mecanismos de avaliação em larga escala, bem como na elaboração da BNCC $(2017 ; 2018)$, pois, parte-se do pressuposto de que o documento traduz a continuidade das concepções educacionais adotadas na década de 1990. Desse modo, o objetivo deste artigo é desenvolver uma reflexão acerca da avaliação em larga escala, a partir da BNCC, como dimensão da política de contenção e liberação no Brasil. O norte investigativo supõe, portanto, o seguinte questionamento: Como a relação entre a avaliação em larga escala e a BNCC expressam a política de contenção e liberação no Brasil?

Para o desenvolvimento da reflexão proposta, estima-se, sobretudo, a compreensão das relações sociais mediante a representação do movimento real e objetivo dos fatos, ou seja, por meio da materialização dos processos históricos de um determinado período. Fundamentandose nesta ideia, o artigo, de cunho bibliográfico e documental, discorre acerca do questionamento proposto.

\section{Avaliação em larga escala e BNCC: expressões da política de contenção e liberação no Brasil}

A avaliação educacional está articulada ao Plano de Desenvolvimento da Educação PDE e ao Fundo de Manutenção e Desenvolvimento da Educação Básica e de Valorização dos Profissionais da Educação - FUNDEB (2006); ao Plano de Metas Compromisso Todos pela Educação (2007) e do Índice de Desenvolvimento da Educação Básica - IDEB (2007), composto pelos resultados advindos principalmente do Sistema de Avaliação da Educação 
Básica - SAEB (1990), compondo um conjunto de ações e diretrizes que alimentam os mecanismos de monitoramento gerencial e de controle das políticas educacionais.

O Saeb foi criado em 1990 para avaliar as turmas de $1^{\mathrm{a}}, 3^{\mathrm{a}}, 5^{\mathrm{a}}$ e $7^{\mathrm{a}}$ séries do ensino fundamental das escolas públicas em língua portuguesa, matemática, ciências naturais e redação. Passou por uma reformulação em 1995 e incorporou uma nova metodologia na construção dos testes e das análises, a Teoria de Resposta ao Item (TRI), proporcionando a comparabilidade entre os resultados das avaliações. Em 1997, o público-alvo passa a ser as turmas de $4^{\mathrm{a}}$ e $8^{\mathrm{a}}$ séries do Ensino Fundamental e $3^{\mathrm{a}}$ série do Ensino Médio das escolas públicas e particulares, avaliando língua portuguesa, matemática, ciências naturais, física, química e biologia, sendo que nesta edição avalia competências e define descritores na formulação dos itens. Em 1999, o Saeb sofreu uma alteração nas áreas/disciplinas e passa a avaliar também História e Geografia (BRASIL, 2020).

Em 2001, passa por nova alteração nas áreas/disciplinas avaliadas e avalia somente língua portuguesa e matemática. Em 2005, a Portaria Ministerial $n^{\circ} 931$ reestrutura o Saeb que passa a ser composto por duas avaliações, a Avaliação Nacional da Educação Básica (Aneb) e a Avaliação Nacional do Rendimento Escolar (Anresc), prova Brasil. Em 2013, por meio da Portaria $n^{0}$ 482, a Avaliação Nacional da Alfabetização (ANA), prevista no Pacto Nacional pela Alfabetização na Idade Certa (Pnaic), passa a compor o Saeb. As turmas avaliadas são $5^{\circ}$ e $9^{\circ}$ ano do Ensino Fundamental, em língua portuguesa, matemática e ciências naturais (sem resultados divulgados), e $3^{\mathrm{a}}$ e $4^{\mathrm{a}}$ série do Ensino Médio em língua portuguesa e matemática (BRASIL, 2020).

Em 2019, o Saeb passou por mais uma reestruturação a fim de se adequar à Base Nacional Comum Curricular (BNCC). As siglas ANA, Aneb e Anresc deixam de existir e todas as avaliações passam a ser identificadas pelo nome Saeb. Um estudo piloto está em desenvolvimento nas Creches e pré-escolas da educação infantil das escolas públicas. No $2^{\circ}$ ano do Ensino Fundamental, são avaliados língua portuguesa e matemática; $5^{\circ}$ e $9^{\circ}$ ano do Ensino Fundamental, língua portuguesa e matemática; $9^{\circ}$ ano do Ensino Fundamental, ciências da natureza e ciências humanas; $3^{\mathrm{a}}$ e $4^{\mathrm{a}}$ série do Ensino Médio, língua portuguesa e matemática (BRASIL, 2020).

Os critérios estabelecidos para as avaliações, conforme Oliveira; Coelho e Castanha (2015), têm maior relação com as habilidades e competências adotadas como prioridade ao mercado, como português e matemática, do que com a realidade brasileira. Assim, fortaleceuse a ideia de que o sucesso e o insucesso dependem do aluno e/ou do professor. 
A proposta sobre a implementação de sistemas de avaliação de desempenho está articulada ao cumprimento das metas para satisfazer as necessidades básicas de aprendizagem de crianças, jovens e adultos, erradicar o analfabetismo e universalizar o acesso à escola. Estas metas foram discutidas e propostas na Conferência Mundial sobre Educação para Todos (1990), que resultou na Declaração Mundial sobre Educação para Todos: Satisfação das Necessidades Básicas de Aprendizagem. Para o Brasil, esta declaração orientou a elaboração do Plano Decenal de Educação para Todos (1993), um conjunto de diretrizes que serviram de referência para a elaboração de legislações e programas educacionais que auxiliaram na implementação da reforma da educação, na década de 1990.

O Plano Decenal de Educação para Todos (1993) pautou-se em uma proposta economicista e tecnicista que foi elaborada no governo de Itamar Franco (1992-1995) e ganhou maior concretude com o governo de Fernando Henrique Cardoso (1995-2003). O Plano Decenal expressou a defesa da universalização do acesso escolar, do repasse de recursos financeiros, a descentralização da gestão e influenciou na elaboração dos Parâmetros Curriculares Nacionais (PCN), sendo as principais discussões: o ensino a distância, o sistema nacional de avaliação, as políticas do livro didático, e a Lei de Diretrizes e Bases da Educação Nacional (LIBÂNEO, 2012).

Neste contexto, a avaliação ganha proeminência como ideia-força do Banco Mundial voltada especificamente ao controle dos resultados e dos impactos da educação no desenvolvimento econômico, social e no alívio dos efeitos da pobreza. Isso pode ser observado no documento "Aprender para hacer realidad la promesa de la educación", de 2018, divulgado pelo próprio Organismo Internacional:

El primer paso para mejorar el aprendizaje en todo el sistema es aplicar indicadores adecuados que permitan verificar si los programas y las políticas están generando los resultados previstos. La información creíble y confiable puede incidir considerablemente en los incentivos de los políticos. En particular, la información sobre el aprendizaje de los estudiantes y el desempeño escolar — si se presenta de manera que resulte relevante y aceptable - contribuye a enriquecer el debate político y a mejorar la prestación de servicios. Asimismo, ayuda a los responsables de formular las políticas a gestionar un sistema complejo (BANCO MUNDIAL, 2018b, p. $16)$.

Pelo exposto, atingir a melhoria da aprendizagem significa obter resultados nos índices avaliativos educacionais. Por isso, a avaliação realizada nos moldes do atual estágio de configuração do capitalismo tem nos seus mecanismos a busca por controlar o sucesso e/ou o fracasso das proposições educacionais (ZANARDINI, 2008). 
O Estado capitalista em seu viés avaliador, por meio dos processos e mecanismos de avaliação, toma os resultados como parâmetros para regular, por exemplo, os investimentos em educação e manejar o controle social por meio da educação (DEITOS, 2010). Desse modo, os testes padronizados de larga escala estão consubstanciados na lógica da racionalidade econômica, em que

La medición del aprendizaje puede mejorar la equidad revelando exclusiones ocultas. [...] la crisis del aprendizaje no es solo un problema para la sociedad y la economía en su conjunto, sino que es también uno de los principales generadores de inequidad y de diferencias cada vez mayores en las oportunidades. Pero dado que en muchos sistemas educativos la información confiable sobre el aprendizaje es sumamente dispar, sobre todo en la escuela primaria y el ciclo inferior de la secundaria, la manera en que el sistema les está fallando a los niños desfavorecidos constituye una exclusión oculta. A diferencia de la exclusión física de la escuela, la falta de aprendizaje suele ser invisible, lo que impide a las familias y comunidades ejercer su derecho a una educación de calidad (BANCO MUNDIAL, 2018b, p. 16).

$\mathrm{Na}$ perspectiva que defende a educação como responsável pela superação dos desajustes sociais, o baixo rendimento escolar observado nos testes avaliativos serve, em parte, para justificar as mazelas sociais. A educação eficiente reverteria os baixos índices dos alunos nos testes avaliativos em larga escala, os dotando de habilidades e competências necessárias para viver na sociedade, sendo ainda a possibilidade de saída da condição de pobreza (ZANARDINI, 2008).

Essa concepção de avaliação está centrada na ideologia da globalização, que dissemina a retórica de alívio/administração dos níveis de pobreza, o qual se insere nos mecanismos de controle do social. Da mesma forma, promove a segurança a serviço do modo de produção capitalista ao manter a regulação do estoque e da qualificação da força de trabalho e proporcionar as condições mínimas de existência (OLIVEIRA; DUARTE, 2005; FIGUEIREDO, 2006; ZANARDINI, 2008). Concomitantemente à continuidade e aprofundamento das reformas da educação, a avaliação ganha centralidade, o Estado a concebe como parte do novo modelo de gestão e como parâmetro para a distribuição de recursos, o que incorpora aspectos de contenção e de liberação num movimento processual em que as medidas educacionais estão atreladas ao movimento do capital, seja como repositório de conteúdo psicossocial ou ao mesmo tempo de controle social. Tanto contenção como liberação são elementos constituintes de um mesmo processo contraditório, como um invólucro ideológico da política educacional vigente.

A relação entre a pobreza e as justificativas de ineficácia da educação, associam-se, com ênfase, à reforma do Estado brasileiro de 1995, uma vez que, considerada necessária para 
o ingresso na chamada sociedade globalizada, articulou a promoção do Estado avaliador. As intenções do Estado "[...] deveriam voltar-se para o permanente controle da eficiência das políticas implantadas e o seu grau de contribuição para a sustentação e manutenção dos interesses do capital.” (ZANARDINI, 2008, p. 99). O Estado avaliador se constitui como alternativa resultante da reforma de um Estado que se pretende não mais promotor direto, mas incentivador e regulador do desenvolvimento, preterindo, por vezes, as políticas sociais mais abrangentes e minimamente universalizadoras.

Os Organismos Internacionais interferem de forma incisiva na educação brasileira após os anos de 1990. O Banco Mundial, por exemplo, ao priorizar a educação básica, que no Brasil corresponde ao ensino fundamental, restringe a aprendizagem mediante as habilidades cognitivas básicas justificadas pelo discurso da centralidade do conhecimento. Assim, conforme a política socioeconômica e ideológica apresentada pelo Banco Mundial, cabe à educação o desenvolvimento de competências:

Se a educação básica e o sistema de desenvolvimento de competências estiverem preparados para atender às demandas dos empregadores, os jovens terão maior chance de acompanhar as mudanças e atendê-las [...]. Portanto, a aquisição de competências na escola, bem como no mercado de trabalho, torna-se parte do capital humano do Brasil e determina as perspectivas de produtividade e inclusão (BANCO MUNDIAL, 2018a, p. 9).

O desenvolvimento de competências, configura-se, desse modo, "[...] como um artifício de retórica e adesão às premissas do neoliberalismo, reduzindo o processo de formação a uma visão geral de racionalidade instrumental, tutelada, restrita e funcional ante o conhecimento universal historicamente produzido" (DOURADO, 2002, p. 240).

No atual contexto socioeconômico e político-ideológico, em que a BNCC orienta e é orientada pela elaboração das políticas de avaliação, cujo princípio de sua formulação se respalda na ideologia globalizante, a ênfase na educação infantil e no ensino fundamental, no que se refere à aprendizagem de habilidades básicas, tende a evidenciar uma das dimensões da política de contenção expressa no controle do acesso ao conhecimento científico, historicamente produzido e acumulado pela humanidade. Observa-se, portanto, que o esvaziamento escolar, curricular e/ou de conteúdos podem ser um indicativo de que a política de contenção está para além do ordenamento normativo (GUERRA, 2020), pois funciona como um mecanismo gerencial de regulação e controle social das políticas educacionais. 
O esvaziamento escolar se expressa, em parte ${ }^{5}$, na definição dos conteúdos, objetivos e finalidades educacionais a serem incorporadas aos currículos escolares. A BNCC, neste contexto, expressa as intencionalidades do empresariado, uma vez que se observa no documento a ausência de referência em relação aos conteúdos científicos, artísticos e filosóficos, tendo, portanto, a ênfase em métodos, procedimentos, competências e habilidades voltadas para a adaptação do indivíduo aos interesses do grande capital, expressando a hegemonia da classe empresarial no processo de elaboração do documento (MARSIGLIA; PINA; MACHADO; LIMA, 2017).

A redução dos conhecimentos a língua portuguesa e matemática representa um esvaziamento no âmbito do currículo, que atinge o contingente populacional atendido pelas escolas públicas. Assim, o esvaziamento dos conteúdos se constitui como forma de negar o acesso ao conhecimento acumulado e sistematizado no campo da ciência, da cultura e da arte à maioria da população brasileira. Nessa direção, a ênfase na aprendizagem para o desenvolvimento de competências está articulada às políticas dos Organismos Internacionais que têm desenvolvido uma lógica empresarial de escola (ANPED, 2018).

A avaliação da educação também está relacionada ao discurso da busca pela qualidade da educação e do ensino. A Lei de Diretrizes e Bases da Educação Nacional (LDB), $\mathrm{n}^{\circ}$ 9.394/1996, indica a necessidade de alcançar a melhoria da qualidade do ensino com a adoção do sistema de avaliação nacional do rendimento escolar. A partir da busca pela garantia do acesso à educação emergem formas de verificação da qualidade, dentre elas, as avalições em larga escala. Do mesmo modo, a valorização dos resultados ganha força, principalmente pelo monitoramento do desempenho individual e, assim, a valorização dos resultados pode implicar na não consideração de outras dimensões do processo educativo (MÉLO; ARAGÃO, 2017).

Conforme Vasconcelos, Leal e Araújo (2020), por meio das avaliações é possível obter informações sobre o desempenho e os resultados do sistema educativo. A avaliação incorpora novos objetivos e finalidades conforme o contexto social e se adequa à dinâmica das reformas educacionais propostas pelos Organismos Internacionais.

O Brasil na década de 1990 definiu um projeto educacional, que se articula ao receituário dos Organismos Internacionais, evidenciando de forma precisa os primeiros passos das reformas educacionais pretendidas, que hoje mostram-se como um campo de disputa ideológica de consolidação e manutenção delineados na BNCC (GONÇALVES, 2020).

${ }^{5}$ Tendo em vista que o artigo trata das dimensões da política de contenção e liberação no Brasil, o termo "em parte", refere-se a uma das características de tais dimensões; ver, dentre outros, Cunha (1979) e Guerra (2020). 
O ponto de partida consiste no enfoque educacional brasileiro alicerçado pela entrada do Movimento Todos pela Educação no país, em 2006, financiado pela iniciativa privada. Nas palavras de Saviani (2007):

\begin{abstract}
Apresentando-se como uma iniciativa da sociedade civil e conclamando a participação de todos os setores sociais, esse movimento se constituiu, de fato, como um aglomerado de grupos empresariais com representantes e patrocínio de entidades como o Grupo Pão de Açúcar, Fundação Itaú-Social, Fundação Bradesco, Instituto Gerdau, Grupo Gerdau, Fundação Roberto Marinho, Fundação Educar DPaschoal, Instituto Itaú Cultural, Faça ParteInstituto Brasil Voluntário, Instituto Ayrton Senna, Cia. Suzano, Banco ABN-Real, Banco Santander, Instituto Ethos, entre outros (SAVIANI, 2007, p. 1243).
\end{abstract}

Pelo exposto, compreende-se que a educação brasileira, principalmente a partir de 2006, passou a coordenar de forma mais articulada e orgânica, por meio de grupos econômicos, os interesses monopolistas do capital financeiro na direção dos pressupostos programáticos para a política educacional. Como se observa pela parceria da organização Todos pela Educação:

Figura 1 - Parceria - Todos pela Educação
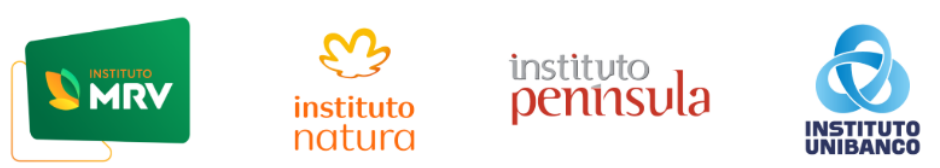

\title{
Itaú BBA
}

\section{MILÚ $\quad$ PRISLLA}
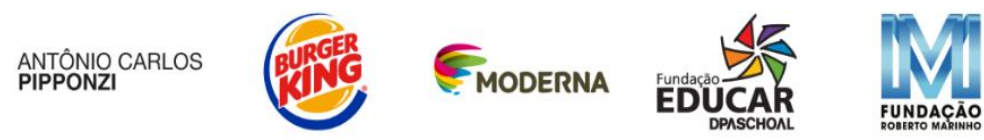

U) CIRELA

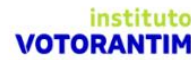

$$
\begin{aligned}
& \text { JAIR } \\
& \text { RIBEIRO }
\end{aligned}
$$




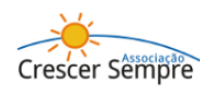

\section{DANIEL} GOLDBERG
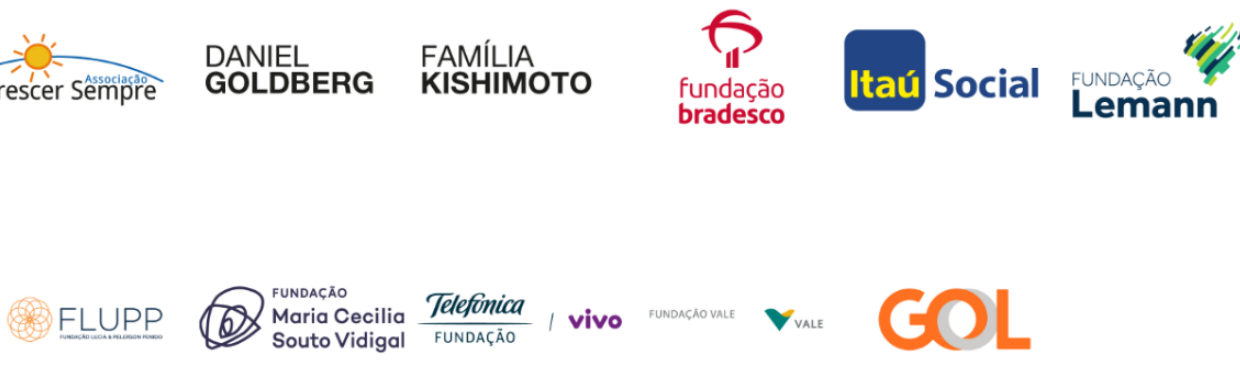

Fonte: Todos pela Educação ${ }^{6}$

Uma verdadeira rede de interesses socioeconômicos e ideológicos coordenados em prol da educação, tecendo teias orgânicas de articulação dos interesses formativos e da promoção política de uma plataforma programática para as políticas educacionais em todos os níveis. A intenção desta demonstração é, acima de tudo, entender o neoliberalismo e o mercado do ponto de vista de influências e práticas, não apenas como um conjunto de ideias flutuantes (BALL, 2014). Existem "amarras" e relações que operam no estabelecimento das políticas educacionais e, por sua vez, o Estado dá a legitimidade e abertura para as organizações nacionais e internacionais, pois expressa uma instituição de maior envergadura no processo de organização social, o tensionamento e as contradições do capital e as relevantes mediações socioeconômicas, políticas e ideológicas para a manutenção e produção da estrutura social vigente (GONÇALVES, 2020).

A exposição dessas parcerias é necessária, na medida em que a BNCC $(2017 ; 2018)$ foi articulada com o apoio do "Movimento pela Base Nacional Comum Curricular", uma organização, que, por sua vez, possui o aporte do "Todos pela Educação". Conforme demonstramos na figura 2 :

6 Disponível em: https://www.todospelaeducacao.org.br/pag/quem-somos/\#bloco_356. Acesso em: 18 mar. 2020 
Figura 2 - Apoiadores da BNCC

\author{
MINISTÉRIO DA EDUCAÇÃO \\ MINISTRO DE ESTADO DA EDUCAÇÃO \\ Mendonça Filho \\ SECRETARIA EXECUTIVA \\ Maria Helena Guimarães de Castro \\ SECRETARIA DE EDUCAÇÃO BÁSICA \\ Rossieli Soares da Silva
}

\title{
PARCERIA
}

Conselho Nacional de Secretários de Educaçao - CONSED

União Nacional dos Dirigentes Municipais de Educaçăo - UNDIME

APOIO

Movimento pela Base

Fonte: Base Nacional Comum Curricular (Educação Infantil e Ensino Fundamental) (2017)

O "Movimento pela Base Nacional Comum Curricular" congrega várias organizações e instituições, dentre elas, o "Todos pela Educação":

Figura 3 - Apoiadores do Movimento pela Base Nacional Comum Curricular MEVIMENTO ACONSTRUÇAODABNCC IMPLEMENTAÇAO QUEMSOMOS BIBLIOTECA ACONTECE NAPRATICA

Instituto Inspirare
Instituto familiar que tem como missão
inspirar inovaçōes em iniciativas
empreendedoras, políticas públicas,
programas e investimentos que
melhorem a qualidade da educação no
Brasil.

Brasil.

\section{Instituto Natura}

Executa e apoia projetos voltados à melhoria da Educação Básica da rede pública, no Brasil e na América Latina, que sejam pautados na eficácia da aprendizagem, na equidade de resultados e na coesão social.

\section{Instituto Unibanco}

Visa ampliar as oportunidades

educacionais dos jovens em busca de investimento corporativo da América uma sociedade mais justa $e$ transformadora, focando sua atuaçẫo na melhoria do Ensino Médio.

\section{Itaú BBA} Latina e faz parte do grupo Itaú Unibanco.

\section{Undime}

A União Nacional dos Dirigentes Municipais de Educação é uma associação civil, fundada em 1986, que reúne dirigentes municipais de educação para construir e defender a educação pública com qualidade social.

Fonte: Movimento pela Base Nacional Comum Curricular ${ }^{7}$

${ }^{7}$ Disponível em: http://movimentopelabase.org.br/quem-somos/. Acesso em: 18 mar. 2020. 
As relações educacionais estabelecidas, principalmente, a partir da aprovação da BNCC, integram um conjunto de soluções privadas, que, segundo Freitas (2018), propiciam uma reforma empresarial na educação. Nas palavras do autor:

Como é típico da reforma empresarial, essas ações, aparentemente sem relação, se articulam em uma engenharia de "alinhamento" (bases/ensino/avaliação/responsabilização), eliminando a diversidade e deixando pouco espaço para a escola ou para o magistério criar, sendo sufocado por assessorias, testes, plataformas de ensino online e manuais igualmente desenvolvidos e padronizados a partir das bases nacionais comuns (FREITAS, 2018, p. 81).

Os princípios neoliberais que norteiam a $\mathrm{BNCC}$ expressam um conteúdo programático de esvaziamento da escola e da sua função de transmitir conhecimentos. Esta interferência no currículo da escola pública expressa o alinhamento neoliberal intensificado pelas reformas do Estado e da educação. Assim, observa-se o cumprimento da agenda do capital no atual contexto social, portanto, o modelo de organização curricular produzido está relacionado à regulação e ao controle da educação escolar, intensificado pelos processos de avaliação e supervalorização das competências e habilidades de cunho psicossocial e socioemocional (MARSIGLIA; PINA; MACHADO; LIMA，2017; COSTA; FARIAS; SOUZA, 2019; GONÇALVES, 2020).

A regulação e o controle educacional se intensificam com a BNCC $(2017 ; 2018)$. Seus princípios não só reiteram uma concepção educacional voltada para a Teoria do Capital Humano $^{8}$, mas, sobretudo, condiciona psíquica e ideologicamente a condição de subserviência na atual forma de sociabilidade por meio das competências socioemocionais, definidas como as dez Competências Gerais da BNCC: 1 - Conhecimento; 2 - Pensamento científico, crítico e criativo; 3 - Repertório Cultural; 4 - Comunicação; 5 - Cultura digital; 6 - Trabalho e projeto de vida; 7 - Argumentação; 8 - Autoconhecimento e autocuidado; 9 Empatia e cooperação; 10 - Responsabilidade e cidadania (MOVIMENTO PELA BASE NACIONAL COMUM CURRICULAR, 2018, p. 2).

As competências socioemocionais, reiteradas na BNCC (2017 e 2018), baseiam-se na expectativa de " [...] transformar o aluno em cidadão mutante, proativo, aspirante ao trabalho e tolerante nos momentos em que se encontre sem emprego" (SHIROMA; EVANGELISTA,

\footnotetext{
${ }^{8}$ A teoria do capital humano foi desenvolvida na década de 1960 e teve como principais formuladores Gary Becker e Theodore W. Schultz. Os fundamentos básicos desta teoria remetem à teoria marginalista e aos princípios do utilitarismo, centrado na busca da máxima utilidade e satisfação dos desejos e prazeres individuais. (SANTOS, 2008, p. 20). Ver Schultz (1967; 1973). SCHULTZ, Theodore W. O valor econômico da educação. Rio de Janeiro: Zahar, 1967. SCHULTZ, T. W. O capital humano: investimentos em educação e pesquisa. Rio de Janeiro: Zahar, 1973.
} 
2003, p. 86). Com vistas a essa formação, cabe a indagação: E a avaliação? A avaliação inserida neste contexto estimula a competição e o individualismo e fornece elementos psicossociais e socioemocionais que justificam as diferenças $e$ as desigualdades socioeconômicas. Por essa análise, seria o mesmo afirmar que:

Essa premissa reconhece na educação um setor de alta produtividade e identifica o sistema educativo com o sistema de mercado: a atividade educativa "deve assumir" as regras do mercado e da competitividade, interação dos que demandam com os que oferecem educação (TORRIGLIA, 2003, p. 102).

A relação entre competição e individualismo é estabelecida pelos índices avaliativos. Tais índices não podem ser compreendidos se desconsiderarmos os interesses econômicos em âmbito global que determinam, na maioria das vezes, a função social da escola preconcebida conforme a divisão internacional do trabalho. A avaliação, nesse sentido, visa assegurar a eficiência do sistema educacional por meio de explicações técnicas e/ou quantitativas.

Para se articular às demandas de um mercado insaciável, as políticas voltadas à educação se configuram na dinâmica das atuais relações sociais de produção. Desse modo, a avaliação se constitui como um mecanismo de responsabilização (accountability), cujo objetivo não está centrado no processo de ensino e aprendizagem voltado para a emancipação/humanização, antes, sua demanda se pauta no "alinhamento" de uma reforma empresarial na educação em que se passa a regulamentar o cumprimento ou não de metas (FREITAS, 2018) como mecanismos alimentadores da dinâmica social e produtiva vigentes. Por isso,

Tendo em vista que a função das Competências Gerais da BNCC é, de acordo com o documento, assegurar o processo de aprendizagem e desenvolvimento dos alunos (BRASIL, 2017), e essas, por sua vez, orientam todo o processo de ensino da educação básica brasileira, cabe analisar que as dez competências propostas na BNCC subsidiam o ordenamento da cognição emocional, facilitando a padronização necessária aos ditames da avaliação em larga escala (GONÇALVES, 2020, p. 44).

A avaliação em larga escala, por essas elucidações, corresponde à adaptação necessária às formas flexibilizantes da economia. Assim, a formação fundamentada em habilidades e competências possibilita o requisito necessário para se tornar o "cidadão do século XXI" e, dessa forma, "Os resultados das avaliações passam a guiar a vida escolar. A elevação da nota da escola é estabelecida como referência de qualidade, o que leva à ocultação sobre as finalidades educativas, favorecendo a captura da ação pedagógica pelo status quo.” (FREITAS, 2018, p. 82, grifo do autor). 
O status quo modernizante requer da "boa educação" a análise pelos resultados. Isso fica evidente na própria BNCC, quando o documento ressalta que se avaliar por meio de competências é uma tendência global:

\begin{abstract}
Essa mesma tendência de elaboração de currículos referenciados em competências é verificada em grande parte das reformas curriculares que vêm ocorrendo em diferentes países desde as décadas finais do século XX e ao longo deste início do século XXI. É esse também o enfoque adotado nas avaliações internacionais da Organização para a Cooperação e Desenvolvimento Econômico (OCDE), que coordena o Programa Internacional de Avaliação de Alunos (Pisa, na sigla em inglês), e da Organização das Nações Unidas para a Educação, a Ciência e a Cultura (Unesco, na sigla em inglês), que instituiu o Laboratório Latino-americano de Avaliação da Qualidade da Educação para a América Latina (LLECE, na sigla em espanhol) (BRASIL, 2017, p. 16).
\end{abstract}

A BNCC é parte de uma política de contenção, ou seja da criação política de mecanismos de controle, classificação e avaliação de resultados e de uma política de liberação, ou seja, da criação de políticas que libertem-se de pressupostos programáticos e formativos e passem a embrenharem-se nos pressupostos socioemocionais como condutores da formação humana no Brasil, uma vez que, visando o estabelecimento de resultados, entendendo a relação currículo e avaliação, determina quais são os conteúdos considerados essenciais para a atual demanda. Nesse sentido, a contenção se expressa na restrição do acesso aos conteúdos científicos e, também, por meio do controle e padronização realizados pelas avaliações em larga escala e a liberação no fornecimento das chamadas habilidades socioemocionais como componentes prioritárias da nova plataforma curricular, compondo o pragmatismo do currículo socioemocional.

\title{
Considerações finais
}

A avaliação educacional para o ranqueamento de resultados compõe o discurso dos Organismos Internacionais, principalmente a partir da década de 1990. Os processos avaliativos, em grande medida, influenciam e interferem no direcionamento de recursos para a educação e para as escolas. A regulação e o controle da educação escolar também podem ser constatados na BNCC, na supervalorização das competências e habilidades socioemocionais em detrimento dos conteúdos científicos.

A implementação da política de contenção e liberação compreende a ênfase na aprendizagem de habilidades básicas e indica determinado controle do acesso ao conhecimento científico. Portanto, a função social da educação e da escola, na perspectiva do 
neoliberalismo, contribui para cumprir a agenda capitalista no atual contexto, respondendo aos processos de regulação e controle do social. Esse processo se expressa nos mecanismos de avaliação em larga escala, e a BNCC, por sua vez, corrobora com a padronização almejada, cuja finalidade é a obtenção de resultados para atingir um determinado ranqueamento educacional que irá contribuir com um disciplinamento socioemocional e econômico para a manutenção das condições ideológicas da ordem social vigente.

A BNCC representa a culminância do acirramento do processo de ajustes sociais e econômicos da década de 1990. Isso se deve ao fato de a BNCC se constituir como uma política de formação que conglomera instituições nacionais e Organismos Internacionais, cuja forma de atuação se dá, principalmente, por meio de terceirizações e parcerias públicoprivada. Uma verdadeira reforma empresarial educacional para a manutenção dos pressupostos formativos socioemocionais e ideológicos necessários para o processo de controle e produção capitalista (FREITAS, 2018; GUERRA, 2020; GONÇALVES, 2020).

Nessa condução, o mercado global educacional, pautado em sistemas de administração, gestão, avaliação e currículo, contribui para definir que conhecimento cultural vale a pena (BALL, 2014). Por isso, a BNCC baseia sua formação em competências socioemocionais (as dez Competências Gerais da BNCC), pois, essas operam como um mecanismo facilitador de testes e responsabilização (accountability) e alimentam o sistema de controle social.

\section{REFERÊNCIAS}

ANPED. A proposta de BNCC do ensino médio: alguns pontos para o debate. Nota da Anped, 2018. Disponível em: http://www.anped.org.br/news/nota-anped-proposta-de-bnccdo-ensino-medio-alguns-pontos-para-o-debate. Acesso em: 09 dez. 2019.

BALL, S. J. Educação Global S. A.: novas redes políticas e o imaginário neoliberal. Trad. Janete Bridon. Ponta Grossa: UEPG, 2014.

BANCO MUNDIAL. Competências e empregos: uma agenda para a juventude. Síntese de constatações, conclusões e recomendações de políticas. Washington, DC, 2018a.

BANCO MUNDIAL. Informe sobre el desarrollo mundial 2018: aprender para hacer realidad la promesa de la educación. Cuadernillo del "Panorama general". Washington, DC: Banco Mundial, 2018b.

BRASIL. Saeb: histórico. Inep, 2020. Disponível em:

http://portal.inep.gov.br/web/guest/educacao-basica/saeb/historico. Acesso em: 18 mar. 2020. 
BRASIL. Base Nacional Comum Curricular (BNCC). Educação Infantil e Ensino Fundamental. Versão final. Brasília: MEC, 2017.

BRASIL. Base Nacional Comum Curricular (BNCC). Ensino Médio. Versão final. Brasília: MEC, 2018.

COSTA, M. da C. dos S.; FARIAS, M. C. G. de; SOUZA, M. B. de. A Base Nacional Comum Curricular (BNCC) e a formação de professores no Brasil: retrocessos, precarização do trabalho e desintelectualização docente. Movimento-Revista de Educação, Niterói, ano 6, n. 10, p. 91-120, jan./jun. 2019.

CUNHA, L. A. Educação e desenvolvimento social no Brasil. Rio de Janeiro: Francisco Alves, 1979.

DEITOS, R. A. Políticas públicas: aspectos teóricos-ideológicos e socioeconômicos. Acta Scientiarum Education, Maringá, v. 32, n. 2, p. 209-218, 2010.

DOURADO, L. F. Reforma do Estado e as políticas para a educação superior no Brasil nos anos 90. Educação \& Sociedade, Campinas, v. 23, n. 80, p. 234-252, set. 2002.

FIGUEIREDO, I. M. Z. Desenvolvimento, globalização e políticas sociais: um exame das determinações contextuais dos projetos de reforma da educação e saúde brasileiras da última década. 2005. 264 f. Tese (Doutorado em Educação) - Universidade Estadual de Campinas, Campinas, 2006.

FREITAS, L. C. A reforma empresarial da educação: nova direita, velhas ideias. 1. ed. São Paulo: Expressão popular, 2018.

GONÇALVES, A. M. Os intelectuais orgânicos da Base Nacional Comum Curricular (BNCC): aspectos teóricos e ideológicos. 2020. 128 f. Dissertação (Mestrado em Educação) Universidade Estadual do Oeste do Paraná, Cascavel, 2020.

GUERRA, D. Contenção e liberação na política educacional brasileira: tendências predominantes na Política de Educação Infantil e do Ensino Fundamental (2006-2016). 2020. 150 f. Dissertação (Mestrado em Educação) - Universidade Estadual do Oeste do Paraná, Cascavel, 2020.

LIBÂNEO, J. C. O dualismo perverso da escola pública brasileira: escola do conhecimento para os ricos, escola do acolhimento social para os pobres. Educação e Pesquisa, São Paulo, v. 38, n. 1, p. 13-28, 2012.

MARSIGLIA, A. C. G.; PINA, L. D.; MACHADO, V. de O.; LIMA, M. A Base Nacional Comum Curricular: um novo episódio de esvaziamento da escola no Brasil. Germinal: Marxismo e Educação em Debate, Salvador, v. 9, n. 1, p. 107-121, abr. 2017.

MÉLO, S. C. B.; ARAGÃO, W. H. Política de avaliação em larga escala: “educação para todos" ou exclusão em nome da "qualidade"? Revista on line de Política e Gestão Educacional, Araraquara, v. 21, n. esp. 2, p. 1152-1164, nov. 2017. 
MOVIMENTO PELA BASE NACIONAL COMUM CURRIULAR. Dimensões e Desenvolvimento das Competências Gerais da BNCC: center for curriculum redesign. 2018. Disponível em: http://movimentopelabase.org.br/acontece/competenciasgerais-debncc/. Acesso em 19 abr. 2018.

OLIVEIRA, D. A.; DUARTE, A. Política educacional como política social: uma nova regulação da pobreza. Perspectiva, Florianópolis, v. 23, n. 02, p. 279-301, jul./dez. 2005.

OLIVEIRA, Q. C. da S.; COELHO, D.; CASTANHA, A. P. Considerações sobre as avaliações em larga escala no Brasil e o papel dos organismos internacionais: eficiência e produtividade x qualidade. Revista on line de Política e Gestão Educacional, Araraquara, n. 19, p. 238-255, jul./dez. 2015.

SANTOS, R. A. Teoria do capital humano: uma análise do caso brasileiro. Análise, Porto Alegre, v. 19, n. 2, p. 18-30, jul./dez. 2008.

SAVIANI, D. O plano de desenvolvimento da educação: análise do projeto do MEC. Educ. Soc., Campinas, v. 28, n. esp. 100, p. 1231-1255, out. 2007.

SHIROMA, E. O.; EVANGELISTA, O. Um fantasma ronda o professor: a mística da competência. In: MORAES, M. C. M. de. Iluminismo às avessas: produção de conhecimento e políticas de formação docente. Rio de Janeiro: DP\&A, 2003. p. 81-98.

SCHULTZ, T. W. O capital humano: investimentos em educação e pesquisa. Rio de Janeiro: Zahar, 1973.

SCHULTZ, T. W. O valor econômico da educação. Rio de Janeiro: Zahar, 1967.

TORRIGLIA, P. L. Argentina: políticas de ajuste e paradoxos na educação. In: MORAES, M. C. M. de. Iluminismo às avessas: Produção de conhecimento e políticas de formação docente. Rio de Janeiro: DP\&A, 2003. p. 99-128.

VASCONCELOS, C. R. D.; LEAL, I. O. J.; ARAÚJO, J. A. de Q. C. Nexos entre gestão, avaliação e o Índice de Desenvolvimento da Educação Básica (IDEB) em escolas públicas. Revista on line de Política e Gestão Educacional, Araraquara, v. 24 n. 1, p. 55-70, jan./abr. 2020.

ZANARDINI, J. B. Ontologia e avaliação da Educação Básica no Brasil (1990-2007). 2008. 208 f. Tese (Doutorado em Educação) - Universidade Federal de Santa Catarina, Florianópolis, 2008.

SHIROMA, E. O.; ZANARDINI, I. M. S. Estado e gerenciamento da educação para o desenvolvimento sustentável: recomendações do capital expressas na Agenda 2030. Revista on line de Política e Gestão Educacional, Araraquara, v. 24, n. esp. 1, p. 693-714, ago. 2020. 


\section{Como referenciar este artigo}

GONÇALVES, A. M.; GUERRA, D.; DEITOS, R. A. Avaliação em larga escala e Base Nacional Comum Curricular (BNCC): dimensões da política de contenção e liberação no Brasil. Revista on line de Política e Gestão Educacional, Araraquara, v. 24, n. esp. 1, p. 891-908, ago. 2020. e-ISSN:1519-9029. DOI: https://doi.org/10.22633/rpge.v24iesp1.14018

Submetido em: 20/02/2020

Revisões requeridas: $30 / 04 / 2020$

Aprovado em: 28/06/2020

Publicado em: 01/08/2020 